
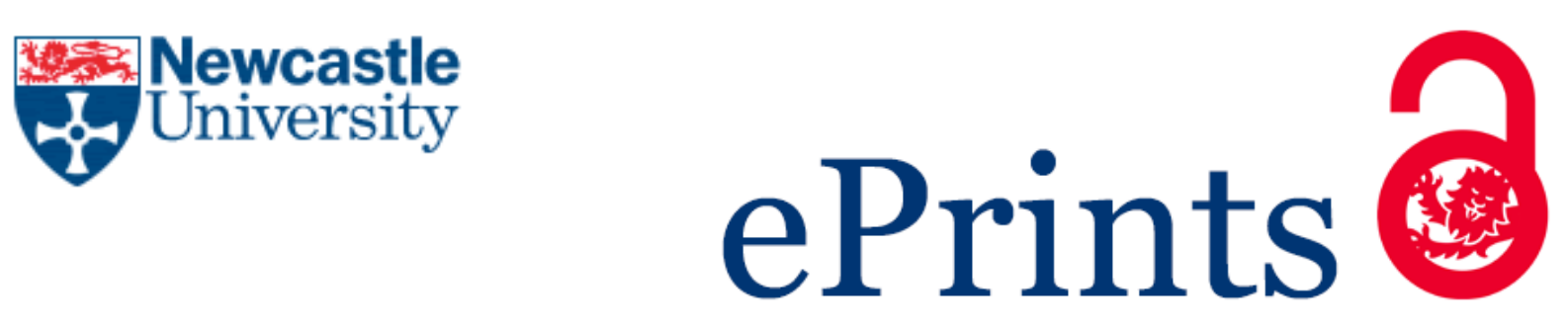

Eapen MS, McAllinden K, Tan D, Weston S, Ward C, Muller HK, Walters EH, Sohal SS. Profiling cellular and inflammatory changes in the airway wall of mild to moderate COPD. Respirology 2017. DOI: 10.1111/resp.13021

\title{
Copyright:
}

This is the peer reviewed version of the following article: [Eapen MS, McAllinden K, Tan D, Weston S, Ward C, Muller HK, Walters EH, Sohal SS. Profiling cellular and inflammatory changes in the airway wall of mild to moderate COPD. Respirology 2017.], which has been published in final form at https://doi.org/10.1111/resp.13021. This article may be used for non-commercial purposes in accordance with Wiley Terms and Conditions for Self-Archiving.

DOI link to article:

https://doi.org/10.1111/resp.13021

Date deposited:

$27 / 03 / 2017$

Embargo release date:

22 March 2018 


\section{Profiling cellular and inflammatory changes in the airway wall of mild to moderate} COPD.

Mathew Suji Eapen ${ }^{1}$ (mathew.eapen@utas.edu.au); Kielan McAllinden ${ }^{1}$

(Kielan.D.McAlinden@student.uts.edu.au); Daniel Tan¹ (dtan1@utas.edu.au ); Steven

Weston ${ }^{1}$ (Steven.Weston@utas.edu.au); Chris Ward³ (chris.ward@newcastle.ac.uk ); Hans

K Muller ${ }^{1}$ (konrad.muller@utas.edu.au) ; Eugene H Walters¹ (Haydn.Walters@utas.edu.au);

Sukhwinder Singh Sohal ${ }^{1,2} *(\underline{\text { sssohal@utas.edu.au }})$

*(Eugene Haydn Walter and Sukhwinder Singh Sohal contributed equally in this study)

${ }^{1}$ NHMRC Centre of Research Excellence for Chronic Respiratory Disease, School of

Medicine, University of Tasmania, Hobart, Tasmania, Australia' and ${ }^{2}$ School of Health

Sciences, Faculty of Health, University of Tasmania, Launceston, TAS, Australia; ${ }^{3}$ Institute

of Cellular Medicine, Newcastle University, Newcastle upon Tyne, Tyne and Wear, UK

\section{Corresponding Author}

Dr Sukhwinder Singh Sohal

School of Health Sciences, University of Tasmania

Locked Bag - 1322, Newnham Drive

Launceston, Tasmania 7248, Australia

Telephone number: +61363245434

Email: $\underline{\text { sssohal@utas.edu.au }}$

\section{Word Count}

Abstract- 193

Text- 2500 


\section{Summary at a Glance}

The study presented, is the first to describe hypo-cellularity in the airway wall tissue of mildmoderate COPDs and the consequential reduction in key inflammatory cell populations. Our current observation contests the currently held simplistic description of airway wall inflammation, which would have therapeutic implications. 


\begin{abstract}
Objective: To enumerate total cells and a number of inflammatory cell differentials in large airways (LA) versus small airways (SA) of mild-moderate COPD, and against appropriate controls.
\end{abstract}

Methods: For LA we used endobronchial biopsies and for SA resected lung tissues. Immunostaining was enumerated (cells per square $\mathrm{mm}$ ) for macrophages, neutrophils, CD4 and CD8 T cells, in the LP up to 150 microns deep for LA and full wall thickness for SA.

Results: We confirmed hypocellularity in the LA, and in the SA wall in smokers and COPD $(p<0.001)$. LA cellularity was least in COPD-current smoker $(C S)(p<0.01)$, while SA cellularity was similar across smoker/COPD groups. LA neutrophils were decreased in COPD-CS $(p<0.01)$, while SA neutrophil counts were unchanged. Compared to controls, LA macrophage numbers in COPD were significantly lower $(p<0.05)$, with SA macrophage numbers unchanged. A significant increase was observed in SA CD8+ cells in both normal smokers $(p<0.01)$ and COPD-CS $(p<0.001)$ but not in LA.

Conclusion: These unique data indicate that the current model for airway wall inflammation in COPD is oversimplified, and contrast with the lumen at least in mild-moderate disease. Any abnormalities in airway wall cell differentials are small, though exaggerated in percentage terms. 


\section{Key words}

Airways, Chronic Obstructive Pulmonary Disease, Inflammation, Inflammatory cells, Lung
tissue

\section{Short Title}

Reduced cellularity and inflammation in COPDs 


\section{Introduction}

COPD is a devastating global disease caused especially by cigarette smoking. The disease is characterized as slowly progressive fixed airway narrowing due to small airway fibrosis and obliteration. Up to fifty percent of COPD patients also go on to varying degree of lung destruction (emphysema) ${ }^{1}$, and as a group, they are highly vulnerable to lung (airway) cancer, suggesting a common pathogenesis ${ }^{2}$.

The literature has reported convincing increases in both innate and adaptive cells in the airway lumen in COPD ${ }^{3-5}$. It has also become accepted that airway wall inflammation also plays a critical role in COPD, but the evidence for this is quite limited. Better understanding of COPD pathophysiology requires more detailed information from airway wall tissues ${ }^{6}$.

There are reports of both increases and decreases in inflammatory cell profiles in the airway wall $^{7-9}$. Selection of patients, inadequate approaches to controls, different sources of tissue acquisition, have been important variables. Studies aimed at relatively early disease before secondary complications such as chronic infection and cancer would be especially valuable for understanding fundamental pathogenesis.

We have reported previously that smoking significantly decreased (rather than increased) large airway lamina propria (LP) total cellularity in mild to moderate COPD subjects ${ }^{10}$. Surprisingly, few groups have examined this in airway tissue. Our hypo-cellularity finding in large airway biopsies questioned whether COPD can truly be regarded as an "airway wall" inflammatory disease. The limited literature evidence on cell differentials in the airway wall is also variable; thus, O'Shaughnessy et al. ${ }^{11}$ showed that there was an increase in CD8+ T cells in COPD while the same cells were demonstrated to decrease progressively from mild to 
moderate to severe COPD by Di Stephano et al, and reports on macrophages and neutrophils have similarly varied in both directions $4,7,12,13$. This lack of consistency for cell differentials in the airway wall and our previous finding of overall hypo-cellularity, led us to believe that a new thorough, systematic investigation was warranted.

We have also probed in more detail than previously the phenotypic specificity of the commonly used macrophage marker CD68 that has been used rather uncritically by respiratory scientists for many years. Evidence from non-respiratory research suggests that this marker is not unique to macrophages alone but are also expressed in other cell types, especially fibroblastic cells ${ }^{14}$.

In the current study, we provide total cellularity, "inflammatory" cell differentials for neutrophils, CD68+ and CD8+ cells in both large and small airway tissue from mild to moderate, stable COPD subjects who were not on medication, and free from clinical infection.

\section{Materials and methods}

\section{Ethics approval}

The Tasmania Health \& Medical Human Research Ethics Committee approved the study (EC00337).

\section{Subjects}

Large airways (LA) biopsies (Ebb) from 72 subjects were recruited through advertisement. Bronchial biopsies (BB) from 20 normal lung function smokers (NLFS), 13 current smoking COPD (COPD-CS) and 14 ex-smokers with COPD (COPD-ES) were compared with 25 
healthy non-smokers. COPD was diagnosed according to GOLD criteria. Subjects with other respiratory diseases, a history of recent acute exacerbation of COPD and those on systemic or inhaled corticosteroids were excluded from the study (Table 1).

Small airways (SA) resected tissues - Forty patients consented for inclusion in this study. The subjects all had primary non-small cell lung cancer (NSCLC), with an approximately equal distribution of squamous and adenocarcinoma. Eighteen had demonstrated GOLD stage I/II COPD on spirometry (FER $<70 \%$ ) and were classified as current or ex-smokers (12 months since smoking cessation). Eleven individuals were current smokers with no evidence of airflow obstruction (NLFS). Subjects with systemic or inhaled corticosteroids were excluded from the study. Tissue from ten non-smokers was obtained from Prof Jim Hogg`s bio-bank at the University of British Columbia and included as a control group (NC) for comparison (Table 1). All these slides were scrutinized by an expert local academic pathologist (HKM) for normality.

\section{Tissue section acquisition and processing}

EBB from the LA and surgical resection material well away from the primary tumour, and containing non-cancer affected SA, and NC tissues were fixed in formalin within minutes of surgery. At processing, tissue blocks of the LA and SA $(<2 \mathrm{~mm}$ internal diameter $)$ were embedded in paraffin.

\section{Immunostaining}

Sections were cut at 3-microns from individual paraffin-embedded blocks. Immunostaining for neutrophils with anti Human Neutrophil elastase (1:100 dilution) (Dako, clone NP57, catalog \# M0752), macrophages with anti Human CD68 (1:400 dilution) (Dako, clone KP1, catalog \# M0814), CD8 and CD4 T cells with anti-CD8 (Leica Novo Castra, clone 4B11, 
catalog \# NCL-CD8-4B11) and anti-CD4 (Leica Novo Castra, clone 1F6, catalog \# NCLCD8-4B11) (1:20 dilution) antibodies respectively, for 1 hour at room temperature. Speciesappropriate isotype-matched immunoglobulin G (X0931 clone DAK-GO1; Dako) was incorporated. Bound antibodies were elaborated using peroxidase-labeled Envision (catalogue number K4001; Dako) and DAB (catalogue number K3468; Dako).

\section{Tissue section quantification}

Computer-assisted image analysis was performed with a Leica DM 2500 microscope (Leica Microsystems), Leica DFC495 camera (Leica Microsystems) and Image Pro Plus 7.0 (Media Cybernetics,) software. Five random fields for both LA and SA were chosen for comprehensive analysis without ad hoc area selection, muscle bundles and glands were excluded from the area surveyed. The observer was blinded to subject and diagnosis.

Briefly: Stained cells were counted in the Lamina Propria (LP) up to 150 microns deep for LA and full thickness airway wall (up to 100 microns deep) in the SA wall; cells per $\mathrm{mm}^{2}$ area were calculated. Stained cells in the epithelium and Rbm were counted and presented per $\mathrm{mm}$ of Rbm length. For total cell counts, haematoxylin stained nuclei were considered as an individual cell, and measured with similar strategies as mentioned above.

\section{Statistical analysis}

Based on the distributions, the data here are represented as mean plus SD, or as medians plus ranges; one way ANOVA parametric tests (Tukey, comparing means across groups) or nonparametric (Kruskal-Wallis, comparing medians across groups of interest) were performed. Specific group differences were then explored as appropriate according to prior hypotheses and the structure of the data using the two-tailed T-test or Mann-Whitney U test.

\section{Results}




\section{Total cells}

Cell density was greater in SA and LA in normal controls $(\mathrm{p}<0.01)$, with cells per $\mathrm{mm}^{2}$ of LP compared to diseased. A decrease in overall cell numbers was observed in both LA LP $(p<0.01)$ and SA wall $p<0.001)$ in COPD when compared to normal non-smokers. In NLFS in large airway, total cell numbers were intermediate $(\mathrm{p}<0.01)$ while in ex-smokers the cell numbers were essentially back to $\mathrm{NC}$ levels though with wider variation $(\mathrm{p}=0.15)$. In the SA, total cell numbers were significantly fewer compared to normal controls in all smoker/COPD groups with little difference between these three (Fig 1 A. and B.).

\section{Neutrophils}

Neutrophil numbers were similar between the SA and LA in non-smoker controls. Neutrophil numbers in the pathological groups in large airways reflected the changes in total cell counts i.e. were reduced with least density observed in COPD-CS $(p<0.01)$. In $S A$, however, neutrophil density was little different from normal in all groups, even if apparently (nonsignificantly) slightly reduced in the NLFS (Fig 1 C. and D.).

\section{CD68+ cells}

We observed two morphologically variable populations of CD68+ cells: round macrophagelike and spindle-shaped cells, which we will refer to as macrophages and fibroblast-like cells respectively (Fig 2 A. and B). In normal LA these CD68+ fibroblast-like cells were much more numerous than macrophages, but in contrast, macrophages dominated the SA CD68+ profile (Fig 3, Fig $2 \mathrm{C}$ and D).

In COPD-CS LA, compared to normal controls, we found fewer macrophages $(p<0.05)$, while in contrast, macrophages in the NLFS were significantly higher $(\mathrm{p}<0.001)$ than normal. In ex-smoker COPD subjects macrophages numbers were close to normal levels. In SA, 
although macrophage numbers were high generally, we found no significant change from normal in their numbers in smoker/COPD groups (Fig 3).

Fibroblast-like cells were slightly higher in normal LA than normal SA but not significantly so $(p=0.09)$. Generally, there was a reduction in all smoker/COPD groups in large airways (significant only for NLFS, $\mathrm{p}<0.01$ ) but fibroblast-like cell densities were unchanged in corresponding small airways (Fig 3).

\section{Lymphocyte sub-types (Fig 4)}

In the LA wall, the lymphocyte populations studied were dominated by the CD8+ phenotype. Both $\mathrm{CD} 8+$ and CD4+ $\mathrm{T}$ cells were found to be lower than normal in the smoker/COPD groups but with some substantial changes in their ratio, especially in the COPD-CS where there was an even more marked relative excess of CD8+ over CD4+ lymphocytes (Fig 4D).

There were many fewer CD4+ T cells throughout the airways, and indeed so few in the small airway that we did not formally count them. In contrast in SA, CD8+ cells tended to be higher than normal across all clinical groups, and especially so in COPD-CS ( $\mathrm{p}<0.01)$.

Inflammatory cell profile in airway epithelium and reticular basement membrane (Rbm)

Overall the inflammatory cell densities in the airway epithelium and Rbm were far lower in comparison to the LP. Although the absolute number was small, a significant increase above normal was observed for macrophages in the epithelium of NLFS when compared to normal controls (Table 2).

\section{Discussion}

In contrast to the current belief of COPD pathology being primarily an inflammatory airway 
disease, we have found that the main finding in the COPD "airway wall" is a reduction in total cellularity at least in the mild-moderate disease. This overall decrease was accompanied by quite small fluctuations in specific inflammatory cell types; the most marked change was a general increase in macrophages in the small airway wall compared to the large airways, but this was in both healthy controls and the diseased as well. Changes in neutrophil numbers largely tracked total cell counts. In the COPD large airway wall, CD8+ T cells were the dominant lymphocyte phenotype over CD4+T cells, and were the only cell type found to be significantly increased in COPD in the small airway wall.

These data are unique in their comprehensive nature, although the importance of sampling the airway wall has been emphasised as needed to compliment more easily obtained luminal cell counts in BAL or sputum ${ }^{15}$. The activation of an innate neutrophil and macrophage reaction in the airway lumen in COPD is well established. This may be because of smoking itself or secondary to infection, which may have a crucial role ${ }^{3,5,16}$.

An earlier report ${ }^{7}$ suggested a moderate increase in the number of neutrophils in the subepithelial airway wall LP in large airway biopsies in mild to moderate COPD in comparison to smokers, but typically this finding is difficult to evaluate since there was no normal control group. Our study suggests, in contrast, that in the airway wall the neutrophils are reduced in stable COPD subjects especially in the large airway LP. These data also suggest that the neutrophils trend back towards normal levels in ex-smoker COPD, suggesting mainly a smoking and to a lesser extent a COPD effect.

For the small airways, published neutrophil data have been both limited and contradictory. Studies conducted by Lams et al. ${ }^{12}$ suggested no change in smokers, which was similar to the conclusion of Hogg et al. in mild COPD subjects ${ }^{17}$, while more recent evidence suggested a 
small increase in neutrophil numbers in mild-moderate COPD patients ${ }^{13}$. Our findings again showed no significant change in COPD subjects in comparison to either NLFS or NC.

The lack of neutrophilia in the airway wall of smokers and COPD could be hypothesised as being due to active egress of neutrophils into the airway lumen, though there was no obvious gradient of wall neutrophils from deep to superficial (epithelium) ${ }^{6,18}$.

We also demonstrated a significant decrease in the number of macrophages in the large airway wall in COPD. Interestingly, macrophages were increased in NLFS, but it seems doubtful that this reaction is related to COPD development. Our macrophage findings are contrary to those of Di Stephano et al. ${ }^{7}$ who suggested a small increase in large airway macrophages in COPD, but they only had smoking controls.

In the current study, we have shown morphological variation in cells expressing the CD68 epitope. Thus, we have observed two phenotypically distinct populations staining with CD68; one is more rounded and darkly staining and considered as typical macrophages phenotypically, while the others more lightly stained, spindly and fibroblast-like. This duality of CD68 staining has been previously shown in other disease tissues and in-vitro ${ }^{14,19-21}$ but so far has received little attention in the respiratory literature.

The small airway wall had far greater number of both "true" tissue macrophages and also the more fibroblast-like CD68+ cells. This would be consistent with small airway fibrosis, but this was belied by the uniform numbers across groups with no signal here for COPD. The macrophage phenotypes have been established in recent years; macrophages can exist in the pro-inflammatory, tissue-destructive M1 phenotype and also as a phagocytic, antiinflammatory, anti-bacterial and pro-fibrotic M2 phenotype ${ }^{22}$. Preliminary data ${ }^{23}$ indicate that in the airway wall there may be phenotype shift from M2 to M1 macrophages, which 
could perhaps be the strongest signal found for a true inflammatory signal but needs confirmation.

The decrease in both $\mathrm{CD} 8+$ and CD4 $+\mathrm{T}$ cells in the large airway LP in COPD are contradictory to findings from O' Shaughnessy et al, where both CD4+ and CD8+ T cell numbers were said to be increased, at least in those with "chronic bronchitis" ${ }^{11}$. The difference in result may be a consequence of this phenotypic co-morbidity absent in our subjects. However, we are in agreement with the one other report ${ }^{8}$.

Our observations on $\mathrm{CD} 8+$ to $\mathrm{CD} 4+\mathrm{T}$ cell ratios did suggest that the large airway wall in COPD is immunologically skewed toward CD8 $+\mathrm{T}$ cells, perhaps a response to the susceptibility of COPD patients to airway viral infection ${ }^{13,24}$. The decrease in CD4+ T cell in COPD could be attributed to the presence of suppressor CD8+ T cells co-expressing CD103, that reduce the proliferation of $\mathrm{CD} 4+\mathrm{T}$ cells ${ }^{24}$, and this should be studied. $\mathrm{CD} 8+\mathrm{T}$ cells were decreased in large airway LP with both smoking and COPD but CD4+ cells markedly more.

The current report is limited to the more highly cited "classical" inflammatory cells. In addition, we have previously observed an increase in mast cells in COPD large airways LP ${ }^{25}$, and are studying small airway mast cells. Others have looked at dendritic cells (CD83+) and found them to be few and variable in number, and reduced essentially to zero in the airways in COPD ${ }^{26}$. Our assessment of CD11c+ dendritic cells in COPD large airway LP found them to be too few to analyse ${ }^{27}$. There are even fewer data available on eosinophils in the airways wall of COPD patients, and these are variable and contradictory ${ }^{9}{ }^{28}$, but absolute numbers were consistently very low.

In conclusion, we have found that there is a marked decrease in total cellularity in both large and small airway walls of smokers and especially in COPD. This change is reflected in a 
decrease in the number of inflammatory cells in the airway wall in these clinical groups. One is left very hard-put to defend the currently prevalent dogma that COPD is inherently an airway (wall) inflammatory disease; at most the small change in CD8+ to CD4+ $\mathrm{T}$ cell balance in the large airways might fit the bill.

\section{Acknowledgements}

Clifford Craig Medical Research Trust (CCMRT)

National Health and Medical Research Council (NHMRC)

University of British Columbia, James Hogg Lung Registry, Vancouver for providing the normal small airway tissue

Financial/nonfinancial disclosure: None

Role of sponsors: N/A 
Table 1. Demographic details and lung function data for participants

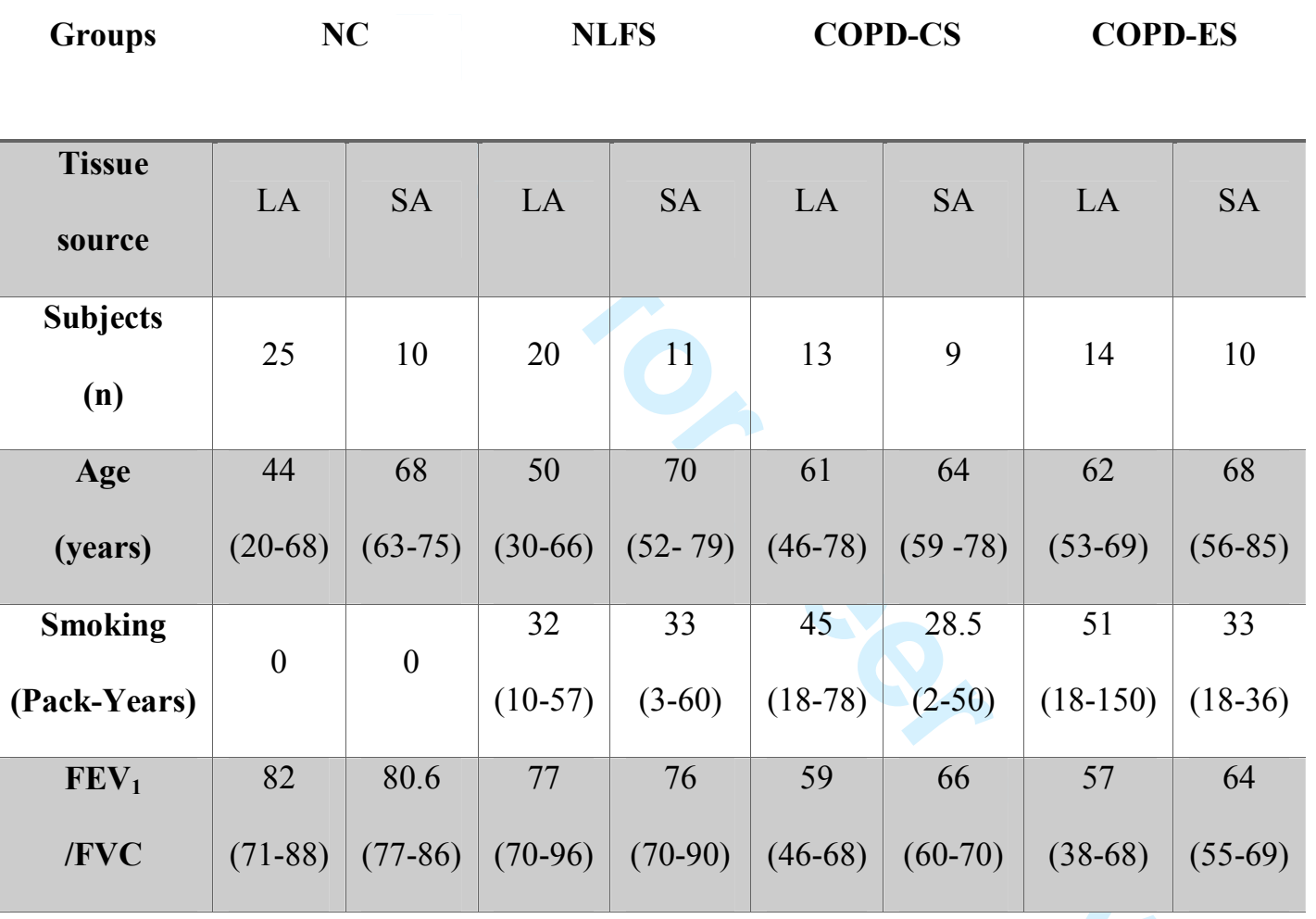

LA- Large Airways; SA- Small Airways;

Data expressed as medians and ranges. NC- normal control; NLFS-normal lung function smokers; COPD-CS current smoker COPD; COPD-ES ex-smoker; 
Table 2.

\begin{tabular}{|c|c|c|c|c|c|}
\hline \multicolumn{6}{|c|}{ Epithelium } \\
\hline $\begin{array}{l}\text { Large } \\
\text { Airways }\end{array}$ & Neutrophils & $\begin{array}{l}\text { Macrophages } \\
(\text { CD68+) }\end{array}$ & $\begin{array}{l}\text { Fibroblasts } \\
(\text { CD68+) }\end{array}$ & CD8+ & CD4+ \\
\hline $\mathrm{NC}$ & $0.4(0-10)$ & $0(0-2.5)$ & $0(0-9.3)$ & $3.7(0-13)$ & $0(0-1.7)$ \\
\hline NLFS & $0.5(0-5.6)$ & $2 * *(0-6.5)$ & $1.1(0-4.9)$ & $7.3(0.5-21.8)$ & $0(0-4.1)$ \\
\hline COPD-CS & $0(0-7.5)$ & $0 \#(0-3.9)$ & $0.5(0-9.3)$ & $5.4(1-23)$ & $0(0-0.9)$ \\
\hline COPD-ES & $0.4(0-2)$ & $1.9 \#(0-1.8)$ & $0.2(0-3.15)$ & $5(1-25.6)$ & $0(0-3.2)$ \\
\hline \multicolumn{6}{|c|}{ Small Airways } \\
\hline $\mathrm{NC}$ & $0(0-0.5)$ & $2.1(0-6.4)$ & $0.5(0-3.2)$ & $0.5(0-9.1)$ & - \\
\hline NLFS & $0(0-1.4)$ & $3.6(0.4-9.4)$ & $1.0(0-6.5)$ & $1.3(0-12)$ & - \\
\hline COPD-CS & $0.5(0-2.4)$ & $3.4(1.2-5.3)$ & $0.5(0-3.6)$ & $2.6(0-11.3)$ & - \\
\hline COPD-ES & $0.2(0-3.7)$ & $2.3(0.3-6.2)$ & $1.0(0-3.6)$ & $0.48(0-2.2)$ & - \\
\hline \multicolumn{6}{|c|}{ Rbm } \\
\hline $\begin{array}{l}\text { Large } \\
\text { Airways }\end{array}$ & Neutrophils & $\begin{array}{c}\text { Macrophages } \\
(\text { CD68+) }\end{array}$ & $\begin{array}{c}\text { Fibroblasts } \\
(\text { CD68+) }\end{array}$ & CD8+ & CD4+ \\
\hline $\mathrm{NC}$ & $3.0(0-13.29)$ & $0(0-0.36)$ & $0(0-2.3)$ & $0(0-4)$ & $0(0-1.1)$ \\
\hline NLFS & $2.5(0.6-9.6)$ & $0(0-1.8)^{*}$ & $0(0-3.4)$ & $0(0-2.7)$ & $0(0-0.4)$ \\
\hline COPD-CS & $0.5(0-10.26)$ & $0(0-0.33)$ & $0(0-2.3)$ & $0(0-2.1)$ & 0 \\
\hline COPD-ES & $0.8(0-7)$ & $0(0-0.17)$ & $0(0-2.3)$ & $0(0-1.9)$ & 0 \\
\hline \multicolumn{6}{|c|}{ Small Airways } \\
\hline $\mathrm{NC}$ & $0.4(0-4.3)$ & $0.0(0-1.5)$ & $0.0(0-1.5)$ & $0(0-1.2)$ & - \\
\hline NLFS & $0(0-0.97)$ & $0.5(0-2.17)$ & $0.4(0-2.17)$ & $0(0-0.4)$ & - \\
\hline COPD-CS & $0(0-1.65)$ & $0(0-1.0)$ & $0.4(0-1.0)$ & $0(0-0.4)$ & - \\
\hline COPD-ES & $0(0-2.5)$ & $0(0-0.45)$ & $0.3(0-0.45)$ & $0(0-0.6)$ & - \\
\hline
\end{tabular}

Cell numbers in the epithelium and Rbm per $\mathrm{mm}$ of $\mathrm{Rbm}$ length. Data are presented as medians (range); $* * \& *$ represents $\mathrm{p}<0.01 \& \mathrm{p}<0.05$ compared to $\mathrm{NC}$, respectively; \# represents $\mathrm{p}<0.05$ compared to NLFS. 


\section{Reference}

1 Sohal SS, Ward C, Danial W, Wood-Baker R, Walters EH. Recent advances in understanding inflammation and remodeling in the airways in chronic obstructive pulmonary disease. Expert review of respiratory medicine. 2013; 7: 275-88.

2 Mahmood MQ, Sohal SS, Shukla SD, Ward C, Hardikar A, Noor WD, Muller HK, Knight DA, Walters EH. Epithelial mesenchymal transition in smokers: large versus small airways and relation to airflow obstruction. International journal of chronic obstructive pulmonary disease. 2015; 10: 1515-24.

3 Pesci A, Balbi B, Majori M, Cacciani G, Bertacco S, Alciato P, Donner CF. Inflammatory cells and mediators in bronchial lavage of patients with chronic obstructive pulmonary disease. The European respiratory journal. 1998; 12: 380-6.

4 Rutgers SR, Timens W, Kaufmann HF, Van Der Mark TW, Koëter GH, Postma DS. Comparison of induced sputum with bronchial wash, bronchoalveolar lavage and bronchial biopsies in COPD. European Respiratory Journal. 2000; 15: 109-15.

5 Pesci A, Majori M, Cuomo A, Borciani N, Bertacco S, Cacciani G, Gabrielli M. Neutrophils infiltrating bronchial epithelium in chronic obstructive pulmonary disease. Respiratory medicine. 1998; 92: 863-70.

6 Persson C, Uller L. Transepithelial exit of leucocytes: inflicting, reflecting or resolving airway inflammation? Thorax. 2010; 65: 1111-5.

7 Di Stefano A, Capelli A, Lusuardi M, Balbo P, Vecchio C, Maestrelli P, Mapp C, Fabbri L, Donner C, Saetta M. Severity of Airflow Limitation Is Associated with Severity of Airway Inflammation in Smokers. American Journal of Respiratory and Critical Care Medicine. 1998; 158: 1277-85.

8 Di Stefano A, Capelli A, Lusuardi M, Caramori G, Balbo P, Ioli F, Sacco S, Gnemmi I, Brun P, Adcock IM, Balbi B, Barnes PJ, Chung KF, Donner CF. Decreased T lymphocyte infiltration in bronchial biopsies of subjects with severe chronic obstructive pulmonary disease. Clinical and experimental allergy : journal of the British Society for Allergy and Clinical Immunology. 2001; 31: 893-902.

9 Saetta M, Baraldo S, Corbino L, Turato G, Braccioni F, Rea F, Cavallesco G, Tropeano G, Mapp CE, Maestrelli P, Ciaccia A, Fabbri LM. CD8+ve cells in the lungs of smokers with chronic obstructive pulmonary disease. American Journal of Respiratory and Critical Care Medicine. 1999; 160: 711-7.

10 Sohal SS, Reid D, Soltani A, Weston S, Muller HK, Wood-Baker R, Walters EH. Changes in Airway Histone Deacetylase2 in Smokers and COPD with Inhaled Corticosteroids: A Randomized Controlled Trial. PLoS ONE. 2013; 8: e64833. 
11 O'Shaughnessy TC, Ansari TW, Barnes NC, Jeffery PK. Inflammation in bronchial biopsies of subjects with chronic bronchitis: inverse relationship of CD8+ T lymphocytes with FEV1. American journal of respiratory and critical care medicine. 1997; 155: 852-7.

12 Lams BE, Sousa AR, Rees PJ, Lee TH. Immunopathology of the small-airway submucosa in smokers with and without chronic obstructive pulmonary disease. American journal of respiratory and critical care medicine. 1998; 158: 1518-23.

13 Utokaparch S, Sze MA, Gosselink JV, McDonough JE, Elliott WM, Hogg JC, Hegele RG. Respiratory viral detection and small airway inflammation in lung tissue of patients with stable, mild COPD. Copd. 2014; 11: 197-203.

14 Kunisch E, Fuhrmann R, Roth A, Winter R, Lungershausen W, Kinne RW. Macrophage specificity of three anti-CD68 monoclonal antibodies (KP1, EBM11, and PGM1) widely used for immunohistochemistry and flow cytometry. Annals of the rheumatic diseases. 2004; 63: 774-84.

15 Ward C, Uller L. 'To measure is to know' (Lord Kelvin). Respirology. 2015; 20: 910.

16 Sethi S, Maloney J, Grove L, Wrona C, Berenson CS. Airway Inflammation and Bronchial Bacterial Colonization in Chronic Obstructive Pulmonary Disease. American Journal of Respiratory and Critical Care Medicine. 2006; 173: 991-8.

17 Hogg JC, Chu F, Utokaparch S, Woods R, Elliott WM, Buzatu L, Cherniack RM, Rogers RM, Sciurba FC, Coxson HO, Pare PD. The nature of small-airway obstruction in chronic obstructive pulmonary disease. The New England journal of medicine. 2004; 350: 2645-53.

18 Porter JC. Exit of leucocytes across the alveolar epithelium worsens lung injury. Thorax. 2011; 66: 1095.

19 Lau SK, Chu PG, Weiss LM. CD163: a specific marker of macrophages in paraffinembedded tissue samples. American journal of clinical pathology. 2004; 122: 794-801.

20 Kunz-Schughart LA, Weber A, Rehli M, Gottfried E, Brockhoff G, Krause SW, Andreesen R, Kreutz M. [The "classical" macrophage marker CD68 is strongly expressed in primary human fibroblasts]. Verhandlungen der Deutschen Gesellschaft fur Pathologie. 2003; 87: 215-23.

21 Gottfried E, Kunz-Schughart LA, Weber A, Rehli M, Peuker A, Muller A, Kastenberger M, Brockhoff G, Andreesen R, Kreutz M. Expression of CD68 in non-myeloid cell types. Scandinavian journal of immunology. 2008; 67: 453-63.

22 Martinez FO, Gordon S. The M1 and M2 paradigm of macrophage activation: time for reassessment. F1000Prime Reports. 2014; 6: 13.

23 Sukhwinder SS, Kielan DM, Steven W, Malik QM, Mathew SE, Eugene HW. Macrophage Phenotype Changes Within the Small Airway Wall in Smokers and Chronic Obstructive Pulmonary Disease (COPD). B43 COPD: PHENOTYPES AND CLINICAL OUTCOMES. American Thoracic Society, 2016; A3513-A.

24 Koch SD, Uss E, van Lier RA, ten Berge IJ. Alloantigen-induced regulatory CD8+CD103+ T cells. Human immunology. 2008; 69: 737-44.

25 Soltani A, Ewe YP, Lim ZS, Sohal SS, Reid D, Weston S, Wood-Baker R, Walters EH. Mast cells in COPD airways: relationship to bronchodilator responsiveness and angiogenesis. The European respiratory journal. 2012; 39: 1361-7.

26 Tsoumakidou M, Koutsopoulos AV, Tzanakis N, Dambaki K, Tzortzaki E, Zakynthinos S, Jeffery PK, Siafakas NM. Decreased small airway and alveolar CD83+ dendritic cells in COPD. Chest. 2009; 136: 726-33.

27 Sohal SS, Reid D, Soltani A, Ward C, Weston S, Muller HK, Wood-Baker R, Walters EH. Evaluation of epithelial mesenchymal transition in patients with chronic obstructive pulmonary disease. Respiratory research. 2011; 12: 130. 
28 Lacoste JY, Bousquet J, Chanez P, Van Vyve T, Simony-Lafontaine J, Lequeu N, Vic P, Enander I, Godard P, Michel FB. Eosinophilic and neutrophilic inflammation in asthma, chronic bronchitis, and chronic obstructive pulmonary disease. The Journal of allergy and clinical immunology. 1993; 92: 537-48.

Figure 1. Total number of cells per square $\mathrm{mm}$ of the airway wall examined: (A). Large Airways; (B), Small Airways. Neutrophils per square mm of the airway wall examined: (C), Large Airways; (D), Small Airways

Figure 2. Illustrates the presence of two morphologically distinct populations of CD68+ in (A). Large Airways and (B). Small Airways (400X magnification). (C) and (D), represent percentages of the total CD68+ for each morphological phenotype.

Figure 3. A, B, C, and D represents the data for CD68+ve round-shaped macrophages and spindle-shaped fibroblast-like cell numbers per square $\mathrm{mm}$ of airway wall examined.

Figure 4. Number of CD8+ve $\mathrm{T}$ cells per square $\mathrm{mm}$ of airway wall examined: (A), Large and (B), Small airways. (C), CD4+ve T cells in LA. (D), Ratio of CD8+ to CD4+ T cells in the LA LP. 
A.

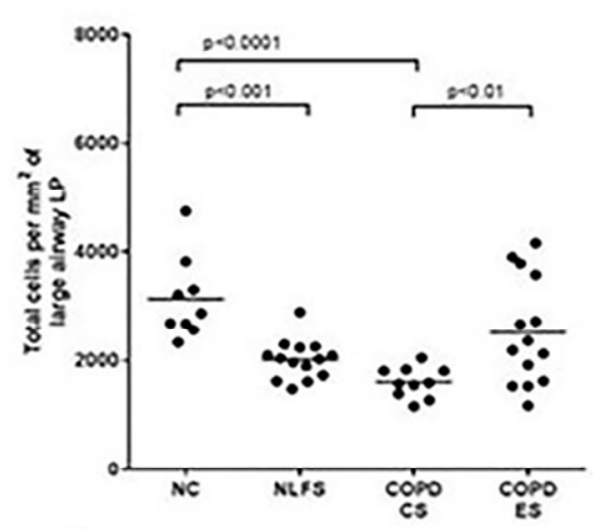

C.

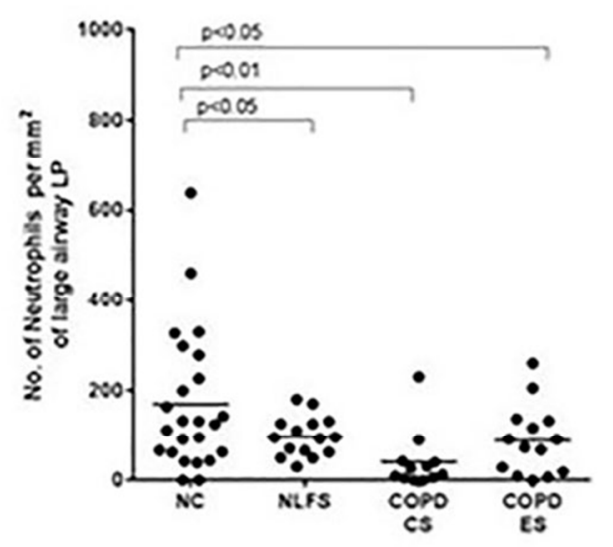

B.

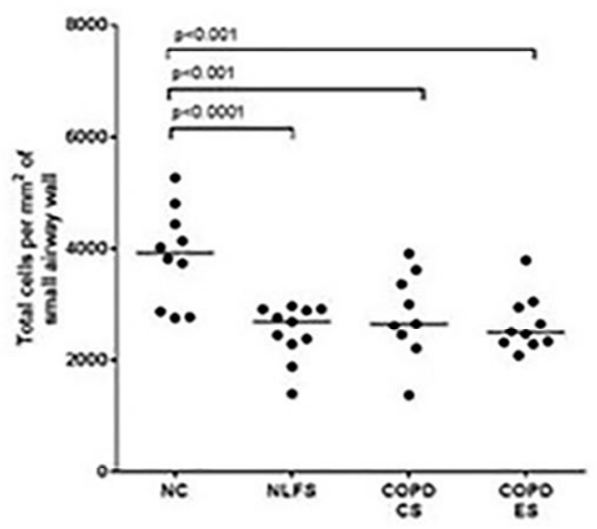

D.

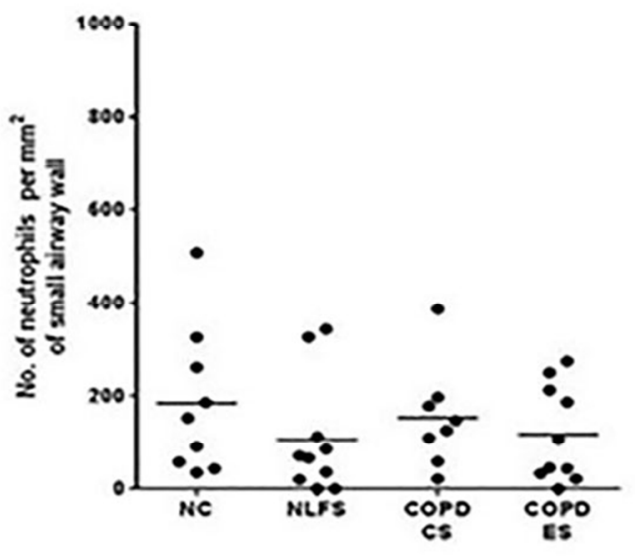

Figure 1. Total number of cells per square $\mathrm{mm}$ of the airway wall examined: (A). Large Airways; (B), Small Airways. Neutrophils per square $\mathrm{mm}$ of the airway wall examined: (C), Large Airways; (D), Small Airways.

$$
140 \times 133 \mathrm{~mm}(200 \times 200 \mathrm{DPI})
$$



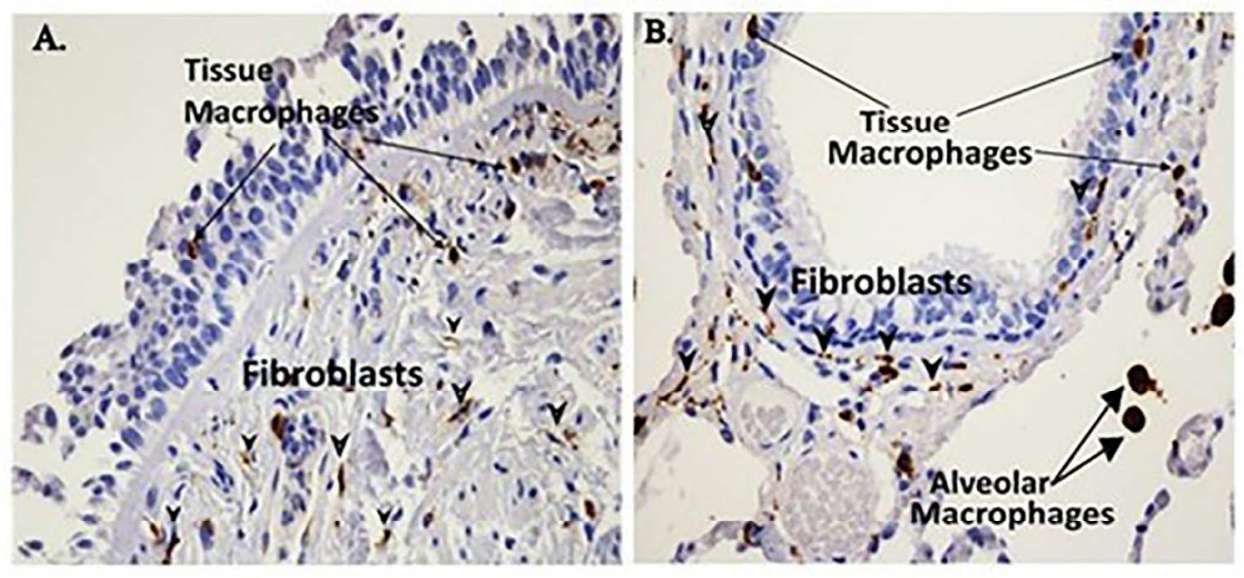

C.

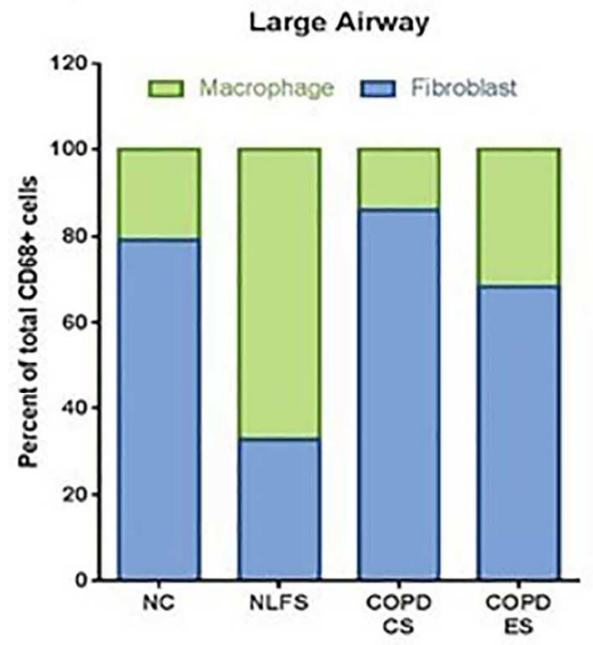

D.

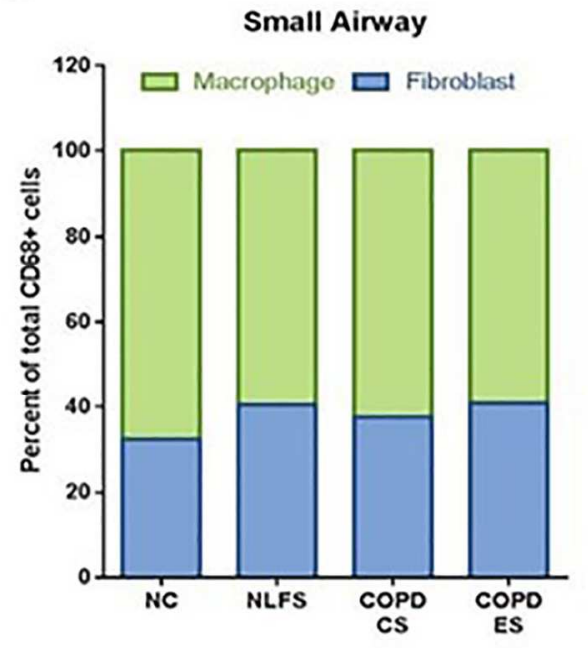

Figure 2. Illustrates the presence of two morphologically distinct populations of CD68+ in (A). Large Airways and (B). Small Airways (400X magnification). (C) and (D), represent percentages of the total CD68+ for each morphological phenotype $140 \times 140 \mathrm{~mm}(300 \times 300 \mathrm{DPI})$ 
A.

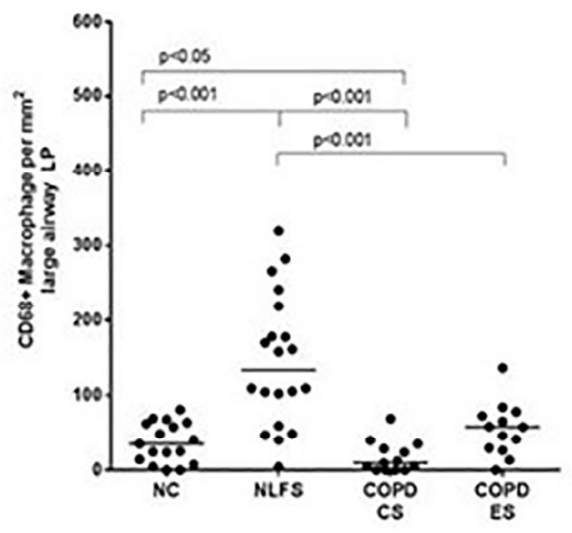

C.

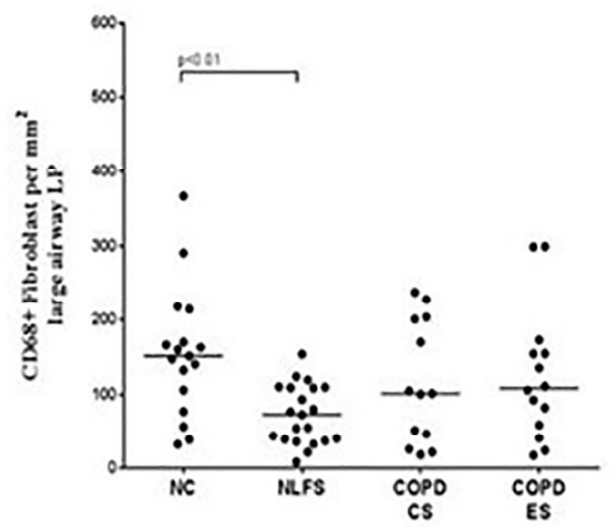

B.

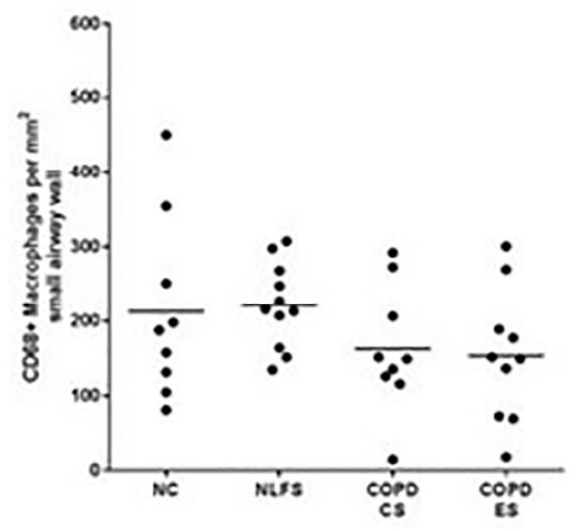

D.

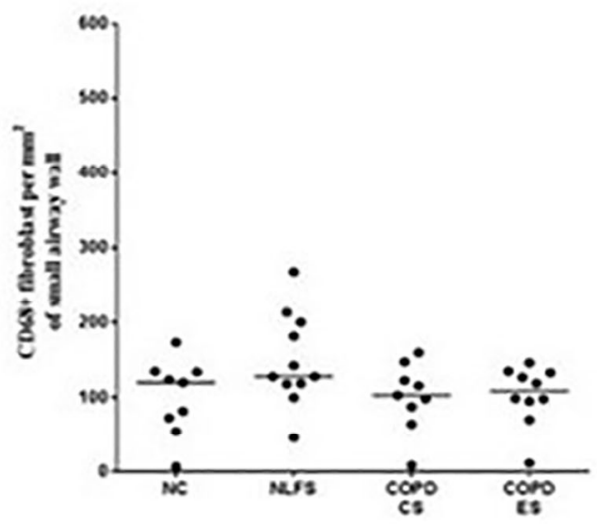

Figure 3. $A, B, C$, and $D$ represents the data for $C D 68+$ ve round-shaped macrophages and spindle-shaped fibroblast-like cell numbers per square $\mathrm{mm}$ of airway wall examined.

$$
140 \times 142 \mathrm{~mm}(300 \times 300 \mathrm{DPI})
$$


A.

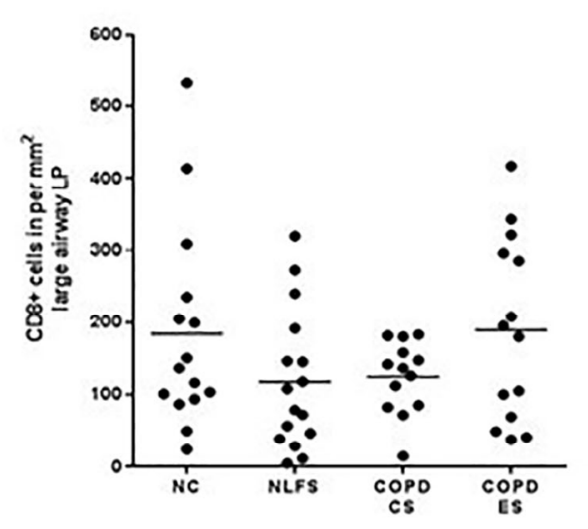

C.

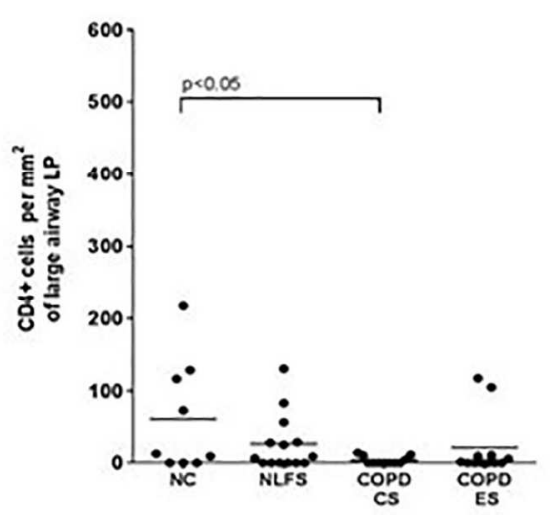

B.

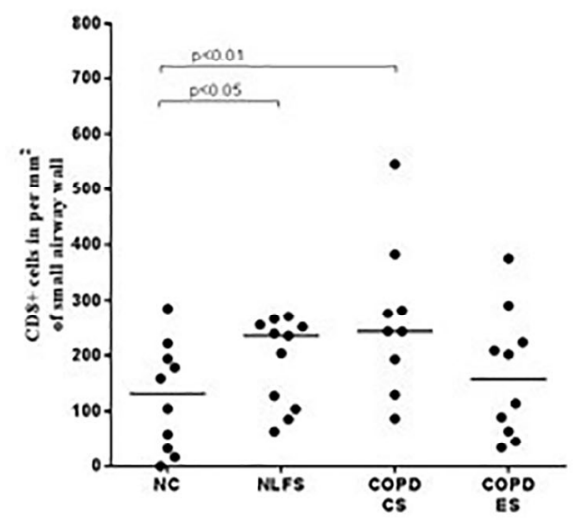

D.

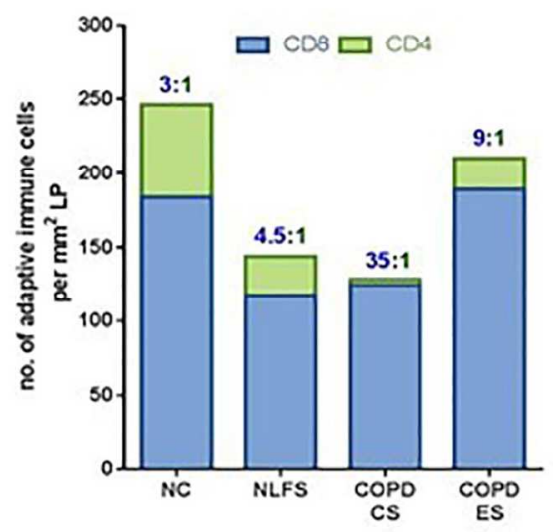

Figure 4. Number of $C D 8+v e T$ cells per square $\mathrm{mm}$ of airway wall examined: $(A)$, Large and (B), Small airways. (C), CD4+ve T cells in LA. (D), Ratio of CD8+ to CD4+ T cells in the LA LP.

$$
140 \times 137 \mathrm{~mm}(300 \times 300 \mathrm{DPI})
$$

